\title{
Effect of the Presence of Basements on the Vibration Period and Other Seismic Responses of R.C. Frames
}

\author{
Jamal Ahmad Alomari \\ Civil Engineering Department, \\ Al-Ahliyya Amman University, \\ Amman, Jordan \\ j.alomari@ammanu.edu.jo
}

\begin{abstract}
The soil-structure interaction (SSI) of R. C. building frames including basements below ground level has been the subject of extended research, mostly in the form of theoretical dynamic analysis. There are different issues concerned with this type of work, as e.g. the location of the base of the structure. Usually, the base of the structure in dynamic analysis or according to the codes is the level at which the lateral displacement is zero. According to this definition, and with the presence of basement floors and the soil mass below, the ground level may not be the base of the structure. The soil stiffness around basement walls has a great effect on the lateral displacement of the basement floor. Another issue is the effect of the presence of the basement floors on the dynamic behavior of the structure. A third issue is the effect of the soil around the basement walls and the soil mass below the foundation in general, which is known as the SSI. In this paper, 3-dimensional regular building frames subjected to seismic loading are analyzed using SAP2000 software. The first frame is a 5-floor, 3-D frame without including the soil mass below the raft foundation and without a basement floor. The second frame is the same frame with a basement floor and with consideration of the soil mass below the raft foundation and around the walls of the basement floor. The third frame is the same frame with consideration of the soil mass below the raft foundation but without the basement floor. Results of the seismic time history analysis and UBC97 response spectrum analysis are presented and discussed.
\end{abstract}

Keywords-soil-structure interaction; soil stiffness; basement floor; seismic analysis; period of vibration; time history analysis; response spectrum analysis

\section{INTRODUCTION}

This paper aims at studying the effect of the presence of basements, including soil-structure interaction (SSI), on the seismic behavior of RC buildings during earthquakes. Conventionally, basement floors have been considered safe during earthquakes, and seismic structural analysis has been conducted to neglect their presence during earthquake excitation. Designers usually consider the structure base at the ground level, and carry out the designs assuming the structure has a fixed base at the ground level, neglecting the presence of the underground floors. In this context, the base of a structure is the level at which the lateral displacement is zero [3]. This issue has been the subject of a lot of theoretical analysis [2-4].
The building codes of practice lack any structural analysis procedures for including the effect of basements with SSI during seismic excitation. They consider the base of the structure is at ground level neglecting the presence of basement floors. For example, UBC97, item 1629.8.2, "Simplified Static", for calculating the base shear, considers the height of a structure measured from ground level and excludes the presence of the basement floors from height calculations, although the presence of basement floors has a considerable effect on the structure behavior during seismic excitation. Periods of vibration, base shear, member forces, and story drifts are considerably changed when SSI and basement floors are considered.

\section{LITERATURE REVIEW}

Authors in [5] carried out an analysis of a 3D, 12+g, RC building frame including 2 basements. They compared the results with the results of the building without basements. They found that due to the presence of basements, roof displacements and base shears were reduced. The period of vibration for the building with basements was found lower than that of the one without basements. Authors in [6] studied the effect of the basement on the seismic response of high-rise buildings and the effect of the seismic loads on the member forces of the basement by studying the behavior of a $\mathrm{G}+15 \mathrm{RC}$ building with basements under seismic loading. Authors in [2] investigated the behavior of a $\mathrm{G}+12 \mathrm{RC}$ building with two basements and shear walls under seismic excitation. They compared the responses, base shear, story drift, axial forces, and periods of vibration, for buildings with and without basement walls. Authors in [4] studied the effect of basements on the structure behavior by carrying out seismic analysis of a 3D model of a 12-story RC building with 4 basements using SAP200. They carried out static, modal, and time history analysis, and concluded that base shear, bending moment and acceleration were reduced, whereas time period and displacement were increased. Authors in [3] carried out structure-soil models for 2- and 6- story buildings built on soft soil deposits, with and without basements, using time domain dynamic analysis. They concluded that the earthquake response of structures with basements is less damaging than without basements. The buildings with basements showed better 
resistance to earthquakes than the buildings without basements as was observed after the earthquakes occurring in Turkey.

\section{FRAMES AND SOIL DESCRIPTION}

To study the effect of the presence of basements and the soil-structure interaction on the dynamic behavior of $\mathrm{RC}$ structures, 3 building frames are considered:

- Case 1 is a 3-D building frame without consideration of the soil below the raft foundation and without a basement floor, called hereinafter as bare frame, as shown in Figure 1.

- Case 2 is a 3-D building frame with consideration of the soil below the raft foundation and with a basement floor as shown in Figure 2.

- Case 3 is a 3-D building frame with consideration of the soil below the raft foundation but without a basement floor as shown in Figure 3.

Figure 4 shows a plan of the building frame for all of the three frames mentioned above.

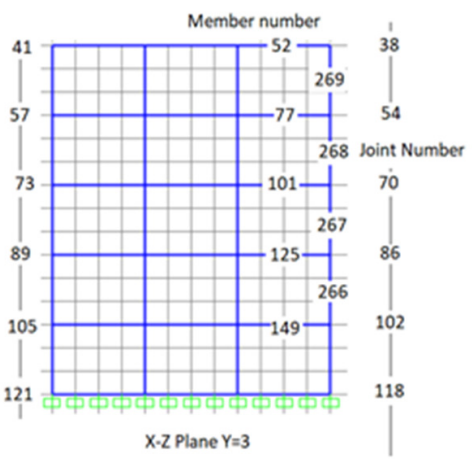

Fig. 1. Case 1: Section of bare frame showing some joints and member numbers at $\mathrm{x}-\mathrm{z}$ plane at $\mathrm{y}=3 \mathrm{~m}$

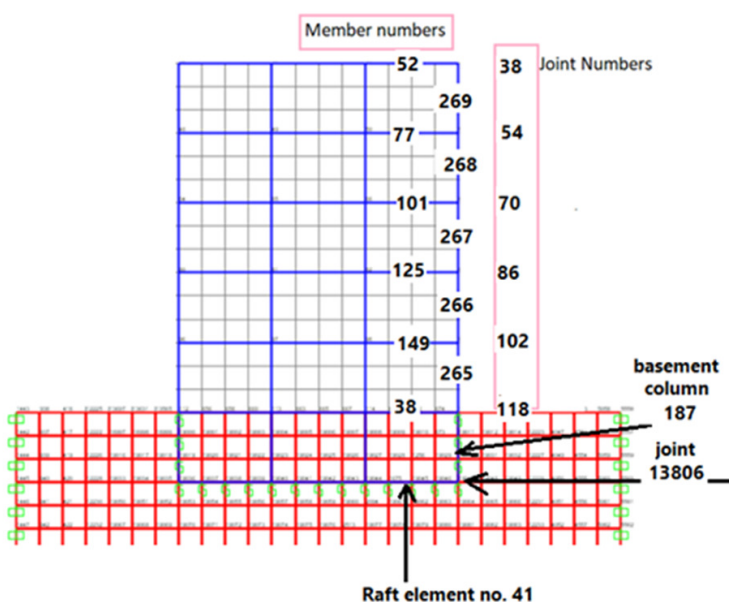

Fig. 2. Case 2: Section of building frame including the soil below raft foundation with one basement floor. Selected joints and members numbers are shown on $\mathrm{x}-\mathrm{z}$ plane at $\mathrm{y}=3 \mathrm{~m}$

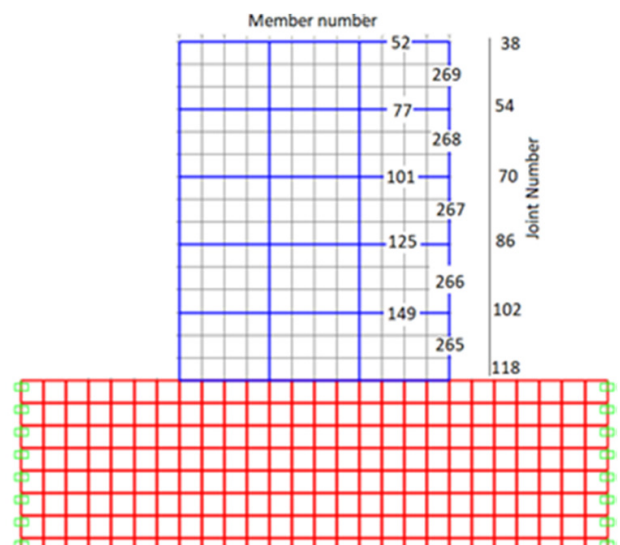

Fig. 3. Case 3: Section of building frame including the soil below raft foundation without a basement floor. Selected joint and member numbers are shown on $\mathrm{x}-\mathrm{z}$ plane at $\mathrm{y}=3 \mathrm{~m}$

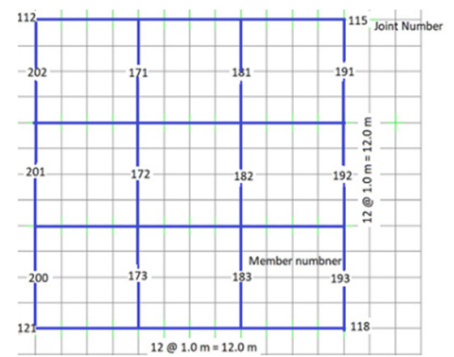

Fig. 4. Plan of the building frame at the level of $z=21 \mathrm{~m}$ showing the raft foundation elements

Each of the frames is a 3D frame. The plan is $12 \times 12 \mathrm{~m}$. Case 1 is the bare frame without the soil mass, and without a basement floor. Case 3 is the frame with the soil mass below foundation but without a basement floor. Both these cases consist of 5 floors with $3.0 \mathrm{~m}$ height for each floor. Case 2 is a frame that includes a basement floor and the soil mass below the raft foundation, and the soil around the basement floor. Case 2 consists of 6 floors including a basement floor surrounded with soil mass on all four sides. The soil mass is modeled by 24 thick shell layers of $1.0 \mathrm{~m}$ thickness. The layers are divided into $1.0 \mathrm{~m} \times 1.0 \mathrm{~m}$ thick shell elements. In plan, the soil mass is $26 \mathrm{~m} \times 26 \mathrm{~m}$, such that it extends $7 \mathrm{~m}$ on each side of the building plan on all four sides. The soil material stiffness is considered 100MPa. The edge joints of the soil mass are considered fixed in the analysis and as such, the rock bed limits are realized at the soil mass boundaries. All columns are $0.5 \mathrm{~m} \times 0.5 \mathrm{~m}$, and all beams are $0.32 \mathrm{~m}$ deep $\times 1.2 \mathrm{~m}$ wide. The building frames are built on a raft foundation of $0.5 \mathrm{~m}$ thickness. The raft elements are considered as $0.5 \mathrm{~m}$ thick $\times$ $4.0 \mathrm{~m}$ wide beam elements. The basement walls are $0.25 \mathrm{~m}$ thick, they are modeled as thin shell elements, and they are divided into $1.0 \mathrm{~m} \times 1.0 \mathrm{~m}$ elements. The soil is considered in contact with the basement walls around the building. Connection between the soil and raft elements and the basement wall elements is realized by compression link elements known as gap elements in SAP2000 software. Such elements are active in compression and have no other effect on the structure's behavior. The stiffness of the gap elements is 
considered as $166770 \mathrm{kN} / \mathrm{m}^{2}$. Concrete compressive strength of all concrete sections is $21 \mathrm{MPa}$. The beams are assumed to carry a uniform load of $15 \mathrm{kN} / \mathrm{m}$. Frames are analyzed for UBC 97 response spectrum, with values of $\mathrm{Ca}=0.4$, and $\mathrm{Cv}=0.4$, and damping of $5 \%$. The frames are also being subjected to time history analysis using N-S El Centro ground acceleration in the $\mathrm{x}$ direction using modal analysis solution and SRSS technique. The results of the analysis are used to compare the structures' responses for column shears, base shears, periods of vibration, and story displacements. All analysis is carried out using SAP200 software.

\section{RESULTS AND DISCUSSION}

SAP2000 software was used to analyze the three described building frames using UBC97 response spectrum and time history analysis was conducted using the N-S El Centro acceleration record. Figure 5 shows the mode shape number 3 of the 3-D frame.

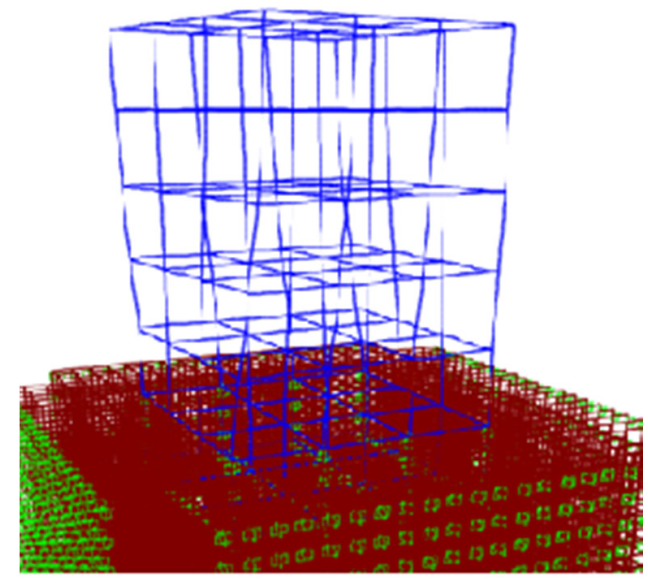

Fig. 5. Mode shape number 3 in a 3D view

\section{1) First Vibration Periods}

Table I shows the first 12 periods of vibration of the frames. It can be seen that the fundamental period of vibration of the bare frame is shorter than that of the other two frames.

TABLE I. VIBRATION PERIODS OF THE THREE BUILDING FRAMES

\begin{tabular}{|c|l|l|l|}
\hline Period No & Case 1 & \multicolumn{1}{|c|}{ Case 2 } & \multicolumn{1}{c|}{ Case 3 } \\
\hline $\mathbf{1}$ & 0.477267 & 0.503704 & 0.529412 \\
\hline $\mathbf{2}$ & 0.477267 & 0.501569 & 0.527399 \\
\hline $\mathbf{3}$ & 0.425421 & 0.435116 & 0.439127 \\
\hline $\mathbf{4}$ & 0.150058 & 0.244263 & 0.286942 \\
\hline $\mathbf{5}$ & 0.150056 & 0.232681 & 0.277906 \\
\hline $\mathbf{6}$ & 0.13518 & 0.224227 & 0.27273 \\
\hline $\mathbf{7}$ & 0.082466 & 0.206354 & 0.252434 \\
\hline $\mathbf{8}$ & 0.082459 & 0.196641 & 0.222605 \\
\hline $\mathbf{9}$ & 0.075614 & 0.18969 & 0.217581 \\
\hline $\mathbf{1 0}$ & 0.057678 & 0.185846 & 0.212107 \\
\hline $\mathbf{1 1}$ & 0.055327 & 0.176478 & 0.193702 \\
\hline $\mathbf{1 2}$ & 0.055317 & 0.172078 & 0.190033 \\
\hline
\end{tabular}

Comparing the fundamental periods of vibration of cases 1 and $3,(0.477 \mathrm{~s}$, and $0.529 \mathrm{~s})$ indicates that the SSI adds flexibility to the building frame. This result is in agreement with the findings of [7]. Structural building codes do not consider the effect of the SSI when they calculate the base shear value. Therefore, such codes in fact overestimate the value of the base shear since the value of the fundamental period of vibration appears in the denominator in their equations, such as in equation 30-4 of the UBC97 code (V=Cv.I.W/R.T). Comparing $\quad 1 / 0.477=2.096 \quad$ with $1 / 0.529=1.890$ reveals that there is an increase in the base shear by $(2.096-1.890) / 1.890 \times 100 \%=10.9 \%$. However, when a basement floor is added to the building frame, as in Case 2, the fundamental period of vibration becomes shorter $(0.504 \mathrm{~s})$. The stiffness added by the basement walls adds stiffness to the structure and causes this reduction in the period of vibration.

\section{2) Shear at the Base of the Structure}

Table II shows the base shear value for the three frames resulting from the analysis. The base shear is in fact the structure base reaction as known in [8]. It acts at the base of the structure which is the level at which the lateral displacement is zero. For the bare frame, it is the foundation level. For the other two frames, it is the bottom of the soil mass, which is $26 \mathrm{~m}$ below the foundation level. The big difference in the values of the base shear occurs due to the huge mass of the soil included in the analysis.

TABLE II. BASE SHEAR IN OF THE THREE BUILDING FRAMES

\begin{tabular}{|c|c|c|c|}
\hline Method of Analysis & Case 1 (kN) & Case 2 (kN) & Case 3 (kN) \\
\hline UBC97 & 416.15 & 30692.69 & 29499.54 \\
\hline $\begin{array}{c}\text { Max base shear in } \\
\text { the x direction }\end{array}$ & 272.866 & 6816.67 & 9144.55 \\
\hline $\begin{array}{c}\text { Min base shear in the } \\
\text { x direction }\end{array}$ & -396.455 & -12721.90 & -14835.02 \\
\hline
\end{tabular}

\section{3) Column Shear Forces}

Tables III-V show the values of shear force in some columns of the three frames resulting from UBC97 and time history analysis. From Table III, it can be seen that shear force in columns of the building frame with basement (Case 2), is much smaller than the one without a basement (Case 3), especially for the upper floor columns. This indicates that the presence of basements reduces shear forces in columns. This can also be concluded by the results shown in Tables IV and V. This result is in agreement with the findings of [9]. On the other hand, comparing the column shear force values for Cases 1 and 3 (including SSI effect), it can be seen that the consideration of SSI effect produces more shear forces in columns. Therefore, it should be noted that this contradicts with the belief that SSI effects produce a decrease of the forces in structures. This is in agreement with [10]. Figures 6 and 7 show the Table values in graphical form.

TABLE III. COLUMNS SHEAR FORCES OF THE 3 BUILDING FRAMES

\begin{tabular}{|c|c|c|c|}
\hline \multicolumn{5}{|c|}{ UBC97 Method of Analysis } \\
\hline Column & Case 1 (kN) & Case 2 (kN) & Case 3 (kN) \\
\hline 269 & 4.76 & 4.07 & 7.99 \\
\hline 268 & 10.73 & 10.26 & 19.06 \\
\hline 267 & 14.72 & 14.50 & 24.34 \\
\hline 266 & 17.70 & 17.50 & 26.80 \\
\hline 265 & 22.48 & 24.34 & 27.16 \\
\hline 187 & & 18.56 & \\
\hline
\end{tabular}


TABLE IV. MAX. COLUMN SHEAR FORCES OF THE 3 CASES RESULTING FROM TIME HISTORY ANALYSIS IN THE X DIRECTION

\begin{tabular}{|c|c|c|c|}
\hline \multicolumn{4}{|c|}{ Time history analysis in the x direction } \\
\hline Column no. & Case 1 $(\mathbf{k N})$ & Case $\mathbf{2}(\mathbf{k N})$ & Case 3 $(\mathbf{k N})$ \\
\hline 269 & 2.47 & 2.84 & 3.49 \\
\hline 268 & 6.26 & 7.34 & 10.12 \\
\hline 267 & 8.93 & 10.60 & 14.60 \\
\hline 266 & 11.90 & 13.08 & 18.73 \\
\hline 265 & 16.48 & 18.10 & 21.44 \\
\hline 187 & - & 10.55 & - \\
\hline
\end{tabular}

Note: Column 187 is a basement column

TABLE V. MIN. COLUMN SHEAR FORCES OF THE 3 CASES RESULTING FROM TIME HISTORY ANALYSIS IN THE X DIRECTION

\begin{tabular}{|c|c|c|c|}
\hline \multicolumn{4}{|c|}{ Time history analysis in the x direction } \\
\hline Column no. & Case 1 (kN) & Case 2 $(\mathbf{k N})$ & Case 3 (kN) \\
\hline 269 & -2.16 & -2.26 & -2.21 \\
\hline 268 & -5.54 & -5.77 & -6.37 \\
\hline 267 & -7.97 & -8.25 & -9.18 \\
\hline 266 & -10.03 & -10.06 & -11.78 \\
\hline 265 & -13.13 & -13.96 & -13.51 \\
\hline 187 & - & -0.23 & - \\
\hline
\end{tabular}

Note: Column 187 is a basement column

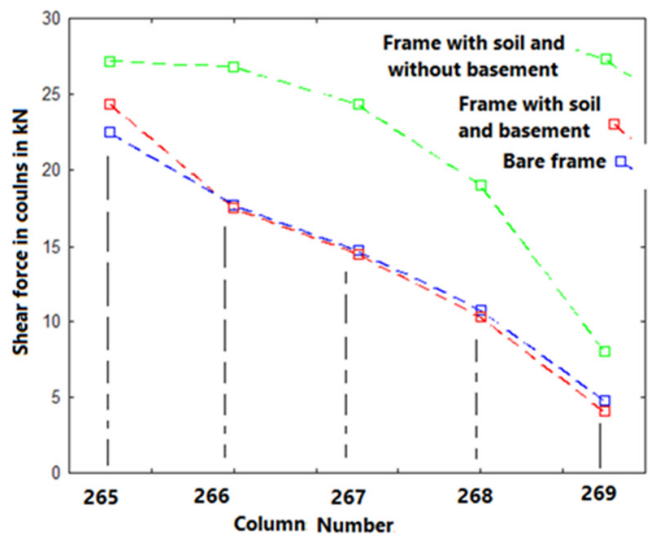

Fig. 6. Shear force in selected columns for the frames resulting from UBC97 response spectrum

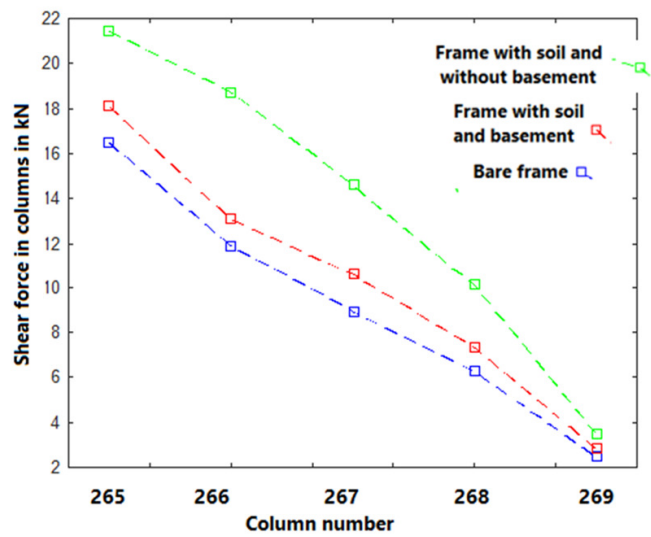

Fig. 7. Maximum shear force in some columns for the frames from time history analysis in the $\mathrm{x}$ direction

\section{4) Joints Displacement}

The lateral displacement of the joints on the extreme of one side of the frames is chosen as a parameter to study the effect of both the presence of a basement floor, and the SSI on the seismic behavior of the structures. The lateral displacements of the joints on the right -hand side of the frames on the $\mathrm{x}-\mathrm{z}$ plane at $y=3 \mathrm{~m}$ are tabulated for the three frames resulting from the UBC97 response spectrum and time history analysis. Tables VI-VIII show these displacements.

TABLE VI. JOINT DISPLACEMENTS OF THE 3 BUILDING FRAMES AS RESULT FROM THE UBC97 ANALYSIS

\begin{tabular}{|c|c|c|c|}
\hline \multicolumn{5}{|c|}{ UBC97 Analysis } \\
\hline Joint number & Case 1 (mm) & Case 2 $(\mathbf{m m})$ & Case 3 $(\mathbf{m m})$ \\
\hline 38 & 6.49 & 7.10 & 11.26 \\
\hline 54 & 5.78 & 6.37 & 9.80 \\
\hline 70 & 4.58 & 5.13 & 7.67 \\
\hline 86 & 2.97 & 3.46 & 5.28 \\
\hline 102 & 1.18 & 1.56 & 3.48 \\
\hline 118 & 0.00 & 0.25 & 3.20 \\
\hline 13806 & - & 0.33 & - \\
\hline
\end{tabular}

TABLE VII. MAXIMUM JOINT DISPLACEMENTS OF THE 3 BUILDING FRAMES

\begin{tabular}{|c|c|c|c|}
\hline Max. displacement resulting from time history analysis \\
\hline Joint No. & Case 1 (mm) & Case 2 $(\mathbf{m m})$ & Case 3 $(\mathbf{m m})$ \\
\hline 38 & 4.18 & 5.22 & 8.72 \\
\hline 54 & 3.77 & 4.71 & 7.84 \\
\hline 70 & 3.06 & 3.83 & 6.43 \\
\hline 86 & 2.04 & 2.61 & 4.56 \\
\hline 102 & 0.84 & 1.22 & 2.45 \\
\hline 118 & 0.0 & 0.15 & 1.11 \\
\hline 13806 & - & 0.14 & - \\
\hline
\end{tabular}

TABLE VIII. MINIMUM JOINT DISPLACEMENTS OF THE 3 BUILDING FRAMES

\begin{tabular}{|c|c|c|c|}
\hline \multicolumn{4}{|c|}{ Min. displacement resulting from time history analysis } \\
\hline Joint number & Case 1 $(\mathbf{m m})$ & Case 2 $(\mathbf{m m})$ & Case 3 $\mathbf{( m m})$ \\
\hline 38 & -3.61 & -4.05 & -5.55 \\
\hline 54 & -3.24 & -3.64 & -4.99 \\
\hline 70 & -2.59 & -2.95 & -4.10 \\
\hline 86 & -1.70 & -2.00 & -2.92 \\
\hline 102 & -0.68 & -0.91 & -1.59 \\
\hline 118 & 0.00 & -0.08 & -0.08 \\
\hline 13806 & - & -0.07 & - \\
\hline
\end{tabular}

A close study of the three Tables shows that the least lateral displacement is in the fixed base structure (Case 1). When soilstructure interaction is considered in the analysis, as in Cases 2 and 3 , it is obvious that the SSI effect produces a significant increase in the story drifts compared to the fixed-base frame. The flexibility of the soil mass below foundation produces a remarkable lateral displacement at the foundation level as shown for joint 118 in Tables VI and VII. Joint 118 in Case 1 is a fixed joint with a zero lateral displacement. The same joint, in Case 2 has a lateral displacement of $0.25 \mathrm{~mm}$ due to the presence of the basement walls. The base of the structure in Case 2 is at the basement bottom not at the ground level as in the fixed base frame of Case 1. Moreover, comparing the displacements at the top of frames of Cases 2 and 3 (at joint 38 ), the effect of the presence of the basement floor reduces the top story drift by a considerable percentage. This can be seen in the following simple calculations: The reduction of the top of frame lateral displacement due to the presence of basement is: 
$(11.26-7.10) / 7.10 \times 100 \%=59 \%$. That is to say, the presence of a basement floor reduces the top story drift of Case 2 by $59 \%$ when UBC97 response spectrum analysis is used. When the time history analysis is used, the reduction is equal to $67 \%$ : $(8.72-5.22) / 5.22 \times 100 \%=67 \%$ (see Table VI).

Similarly, it is possible to find the effect of the SSI on the story drift by comparing the displacements of Cases 1 and 3 . When UBC97 response spectrum analysis is used, SSI increases the top story drift by $73 \%$ : $(11.26-6.49) / 6.49 \times 100 \%=73 \%$ (Table VI). When time history analysis is used, the top story drift increases by $50 \%$ : $(8.72-4.18) / 4.18 \times 100 \%=50 \% \quad$ (Table VI). The story displacements in Table VIII show similar results. Therefore, it can be concluded that the frames with SSI included exhibited much larger story drifts than the fixed base structures. Moreover, the presence of a basement floor reduces the story drifts by a big percentage. In both cases, there are many factors affecting the changes in the story drifts, including the number of basement floors, the extension of the soil mass below, on the sides of the foundation and on the sides of the basement floors, the properties of the soil mass, the properties of the link gap elements, and the properties of the basement walls. Figures 810 show the results in graphical form.

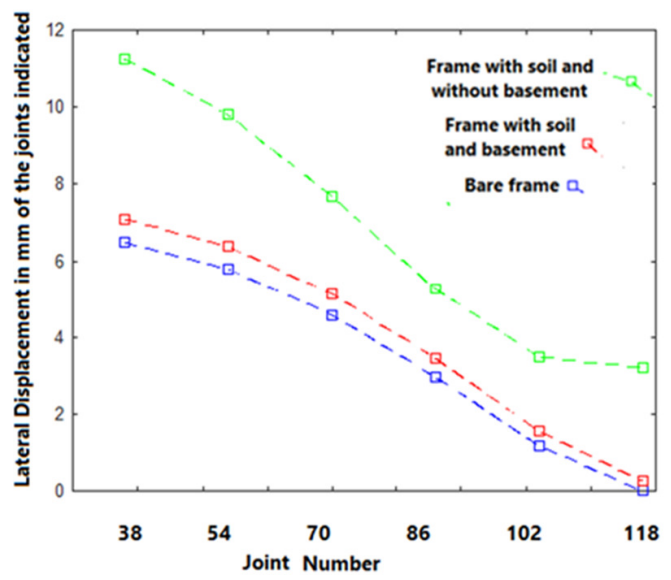

Fig. 8. Joint displacement at selected joints of the three frames resulting from UBC97 response spectrum analysis

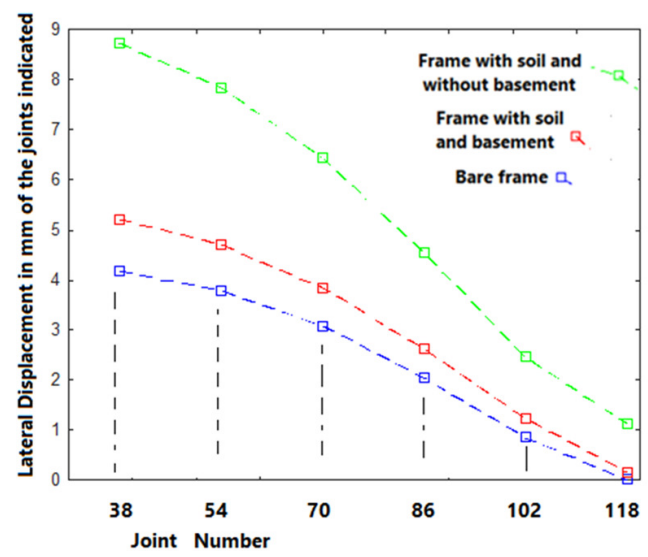

Fig. 9. Joint displacement at selected joints of the three frames resulting from time history analysis in the $\mathrm{x}$ direction

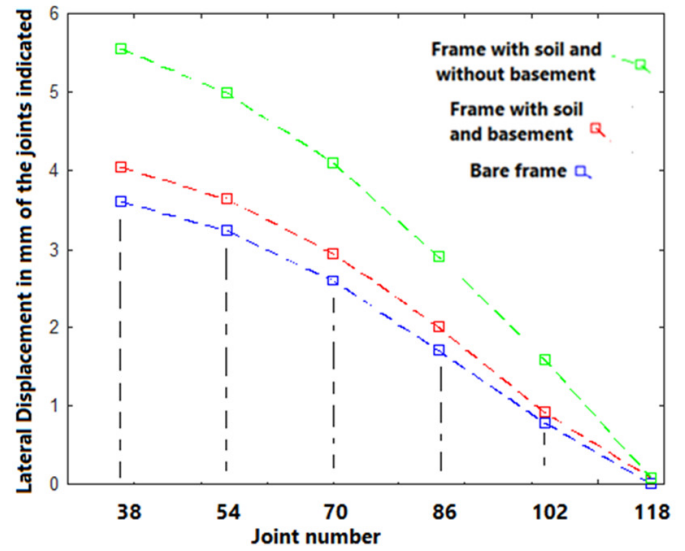

Fig. 10. Maximum joint displacement at selected joints of the three frames resulting from UBC97 response spectrum analysis

\section{CONCLUSION}

Three regular RC frame buildings have been analyzed by UBC97 response spectrum and time history analiiysis using the $\mathrm{N}-\mathrm{S}$ El Centro acceleration record. The aim was to study the effect of the basement floor and the soil-structure interaction on the dynamic response of the buildings. From the results the following conclusions can be drawn:

- When the SSI and the presence of basement floors are included in the dynamic analysis of structures, as compared to fixed base structures, the changes in the values of the story drifts, periods of vibrations, columns shear forces, and other structures' responses, are too large to be ignored.

- There are many factors affecting the extent of the effects of the SSI and the basement floors on the dynamic behavior of structures. These include the number of basement floors, the soil mass extension below and around the structures, the properties of the soil mass, the basement wall properties, the type of connection between the soil mass and the structure elements, the regularity of the frames, and the type of seismic excitation. Therefore, more research is still needed in order to conclude at any governing formulas to quantify such effects for code writing.

- For the three frames considered with different conditions of soil, and basement floor, it is concluded that the SSI imparts flexibility to the structures, the story drifts increased by $50 \%$ or more, and the column shear forces increased by unequal percentages, with the upper floors columns experiencing more increase in the shear force than the lower columns.

- For the two frames of considered Cases 2 and 3, the presence of a basement floor has a remarkable effect on the structure seismic analysis, and caused the top floor lateral displacement to be reduced by $59 \%$ and $67 \%$ for the UBC response spectrum and time history analysis respectively. It is concluded that the presence of a basement floor reduces the floor drifts by a large amount, and therefore underground basements are beneficial to the structures. 


\section{REFERENCES}

[1] D. J. Kelly, "Location of Base for Seismic Design", Structure Magazine, Vol. 2009, No. 12, pp. 8-11, 2009

[2] B. Raghava Maheedhar, M. Arun Kumar, S. Nagarjuna, C. V. Siva Rama Prasad, "Analysis and Design of g+12 storey building with shear wall effect with two basements", International Research Journal of Engineering and Technology, Vol. 5, No. 5, pp. 396-401, 2018

[3] N. Caglar, S. Sert, M. S. Imbabi, A. H. Serdar, "The Effect of a Basement Story on the Earthquake Response of RC Buildings Constructed on Soft Surface Soil”, 3rd International Symposium On Innovative Technologies In Engineering And Science, Valencia, Spain, June 3-5, 2015

[4] N. Chandran, A. P. Rajan, S. Syed, "Seismic Analysis of Building with Underground Stories Considering Soil Structure Interaction", International Journal of Emerging Technology and Advanced Engineering, Vol. 4, No. 11, pp. 112-117, 2014

[5] M. Arun Kumar, B. Raghava Maheedhar, G. Janakiram Goud, "Comparative Study on Analysis and Design of G+12 Stories Building With and Without Basement Walls of Two Basements", International Journal of Engineering and Techniques, Vol. 4, No. 2, pp. 240-245, 2018

[6] J. Sravani, V. A. Reddy, "Earthquake Analysis of High Raised RC Framed Building by Response Spectrum Method", International Journal of Trend in Research and Development, Vol. 4, No. 1, pp. 580-585, 2017

[7] H. Turkia, N. Lahbari, "A Analytical Model For Vibration Period With SSI Of R/C Structures", IOSR Journal of Mechanical and Civil Engineering, Vol. 12, No. 2, pp. 110-120, 2015

[8] https://www.csiamerica.com/products/sap2000

[9] R. C. Ravi Kumar, S. Sameer, P. Sandeep Reddy, "A Study on the Behavior of a Multi-Storied Building With Soil-Structure Interaction", ARPN Journal of Engineering and Applied Sciences, Vol. 11, No. 23, pp. $13760-13765,2016$

[10] O. Bogdan, D. M. Ghiocel, D. Cretu, "Seismic-Soil-Structure Interaction (SSI) Effects For a Different Type of Buildings in Dense Urban Area", Second European Conference on Earthquake Engineering and Seismology, Istanbul, Turkey, August, 25-29, 2014

\section{AUTHORS PROFILE}

Jamal Alomari is an assistant professor of Structural Engineering, teaching at Al Ahliyya Amman University in the Civil Engineering Department. His main scientific intersts lie in the area of dynamic analysis and earthquake engineering of structures. 